\title{
Study of Paraffin/H2O2 Hybrid Rockets for Launching Nanosats
}

\author{
Fernando S. Costa, Ricardo A. Contaifer and José Albuquerque-Jr \\ Instituto Nacional de Pesquisas Espaciais, C. Paulista, São Paulo, 12630-000, Brazil \\ Stephen B. Gabriel and Rodrigo I. Marques \\ University of Southampton, Southampton, SO171BJ, UK
}

\begin{abstract}
Hybrid rockets using green propellants have been considered for launching nanosats into low Earth orbit (LEO). This work determines the preliminary mass distribution and sizing of hybrid rockets using $98 \% \mathrm{H}_{2} \mathrm{O}_{2}$ and solid paraffin mixed with aluminum as propellants. An iterative process is used to calculate the rocket performance characteristics and to determine the inert mass fraction from given initial conditions. It is considered a mission to place a $20 \mathrm{~kg}$ payload into a $300 \mathrm{~km}$ circular equatorial orbit by air launched and ground launched hybrid rockets.
\end{abstract}

\section{Introduction}

$\mathrm{H}$ ybrid rocket technology is known for more than 60 years, however only in the 1960's its safety characteristics motivated a significant research. Nowadays, the need for green propellants (propellants with low toxicity and low pollutant characteristics), the requirements of safe operation and storability, low cost missions, and the interest for launching small payloads and nanosats into LEO made hybrid rockets more attractive.

Hybrid propulsion systems employ propellants in different phases, being the most usual hybrid systems with a solid fuel and a liquid oxidizer. Since they use only one liquid propelllant, they require only one liquid line and a relatively simple injection system, as compared to liquid bipropellant systems which require two separate liquid lines and a complex injection plate in order to collide and mix the fuel and oxidizer jets. The control of the oxidizer flow rate in hybrid systems allows several starts and an accurate control of the thrust level.

The safe operation of hybrid propulsion systems is related to the separation of fuel and oxidizer, differently from solid systems which mix fuel and oxidizer in the grain. Another important safety characteristic is the independence of the regression rate with respect to the chamber pressure, making hybrid systems safer than solid systems if pressure peaks do occur.

The main disadvantage of hybrid rockets is the low thrust level attainable, due to the relatively low regression rates of conventional solid fuels, making necessary the use of a large number of ports. Some methods to increase the regression rate are known, such as i) insert screens or mechanical devices in the ports to increase the turbulence level; ii) use of metallic addictives; iii) use of oxidizers mixed within the solid fuel; iv) increase the surface rugosity adding small solid particles. However, these solutions have also undesirable characteristics.

Recently, it was developed in the Stanford University and in the Ames-NASA Research Center a new paraffinbased fuel whose regression rate is approximately three times higher than conventional hybrid fuels ${ }^{1,2,3}$. Promising results were obtained by several researchers ${ }^{3,4,6,7}$ using paraffin with different oxidizers: LOX, GOX, nitrous oxide $\left(\mathrm{N}_{2} \mathrm{O}\right)$ and $\mathrm{HTP}\left(\mathrm{H}_{2} \mathrm{O}_{2}\right)$.

The hydrogen peroxide $\left(\mathrm{H}_{2} \mathrm{O}_{2}\right)$ is a well-known oxidizer and has been used for decades in rockets, gas generators, helicopter rotors and rocket belts ${ }^{8,9}$. It was used, for example, as an oxidizer in the British rocket Black Knight. There are some advantages of using hydrogen peroxide as oxidizer: relatively high density, easy of handling, non-toxicity and mono-propellant characteristics ${ }^{10}$. Turbo-pumps and pressurization systems can utilize the energy released during peroxide decomposition and its products in order to simplify the tank pressurization systems. HTP (High Test Peroxide) is similar to nitroglycerin in terms of shock sensitivity, and explodes with the same strength than the same quantity of $\mathrm{TNT}^{11}$, however Ref. (12) reports that changes in the propellant manufacturing process may have significantly improved peroxide properties in the last decades.

The objective of this work is to make a preliminary analysis of the mass distribution of hybrid propulsion systems and to compare the performance of air launched and ground launched hybrid rockets. The propellants are an aqueous solution of $98 \% \mathrm{H}_{2} \mathrm{O}_{2}$, in mass, burning with solid paraffin mixed with $10 \%$ aluminum, in mass. The

1

American Institute of Aeronautics and Astronautics 092407 
effects of mixture ratios, thrust/weight ratios and chamber pressures are analyzed. Three stage rockets are considered for placing a $20 \mathrm{~kg}$ nanosat into a low Earth circular equatorial orbit at $300 \mathrm{~km}$.

\section{Mass Distribution of Hybrid Rockets}

The optimization of a propulsion system to perform a given mission is a complex task, since there are several coupled variables which depend on time and on rocket trajectory. The mass distribution analysis will also depend on the component level considered.

To place a satellite into a specified orbit around Earth, the launching vehicle must attain a characteristic velocity, $\Delta V$, to overcome the Earth gravitational field and the air drag, to make maneuvers and to attain a prescribed orbital velocity. Historical data of several launching vehicles indicate $\Delta V$ values between 8800 and $9300 \mathrm{~m} / \mathrm{s}$ to place satellites into $\mathrm{LEO}^{13}$. In this work it was adopted a conservative $\Delta V=9300 \mathrm{~m} / \mathrm{s}$ for ground launched rockets and a $\Delta V=8700 \mathrm{~m} / \mathrm{s}$ for air launched vehicles, based on data from the American air launched rocket Pegasus.

Usually, a rocket must have several stages to transport a significant payload fraction, above $1 \%$, into an orbit around Earth. The increase in payload fraction with a larger number of stages is significant up to 3 or 4 stages, but above 4 stages, the propulsion system complexity grows considerably, with consequent reduction in reliability and no significant increase on payload fraction. In this work, hybrid rockets with three stages are studied, assuming a uniform distribution of characteristic velocities among stages.

Initially, in order to determine the rocket mass distribution, it is required to estimate the inert mass fraction of all stages. The inert mass of a stage is the total initial mass less the propellant and the payload masses.

The inert mass fraction, $f_{\text {inert } t}$, of the $j$-stage $(j=1,2$ or 3$)$ is defined by

$$
f_{\text {inert }, j}=m_{\text {iner }, j} /\left(m_{\text {prop }, j}+m_{\text {iner }, j}\right)
$$

where $m_{\text {prop }, j}$ is the propellant mass and $m_{\text {inert }, j}$ is the inert mass of the $j$-stage.

The propellant mass of the $j$-stage is calculated by

$$
m_{p r o p, j}=m_{p a y, j}\left(1-f_{\text {inert }, j}\right)\left(e^{\Delta V_{j} / s p p_{j} g_{o}}-1\right) /\left(1-f_{\text {iner }, j} e^{\Delta V_{j} /\left\langle s p_{j} g_{o}\right.}\right)
$$

where $m_{p a y, j}$ is the payload mass, $I s p_{j}$ is the specific impulse, $g_{o}$ is the gravity acceleration at sea level, and $\Delta V_{j}$ is the characteristic velocity of the $j$-stage. The specific impulse can be related to the exit velocity of combustion products, $V_{e, j}=g_{o} I s p_{j}$, and is obtained from NASA CEA $2004 \operatorname{code}^{14}$.

The payload mass of a given stage is the total initial mass of all upper stages, and the payload mass of the last stage is the nanosat mass. The inert mass is calculated in terms of the assumed inert fraction:

$$
m_{\text {iner }, j}=f_{\text {iner }, j} m_{\text {prop }, j} /\left(1-f_{\text {iner }, j}\right)
$$

and the total initial mass, $m_{T, j}$, is calculated by

$$
m_{T, j}=m_{\text {iner }, j}+m_{p r o p, j}+m_{p a y, j} .
$$

The $F / W$ ratio relates the thrust, $F$, and the weight, $W$, of a rocket, and is generally expressed in $g$-number. This ratio (acceleration) is limited to a range. It can not be high to avoid damages to the equipment, or to not harm an eventual crew. Obviously it cannot be smaller than unity, but should be small to optimize the performance, especially in the first stage which has to overcome a significant air drag. The thrust to obtain a specified $j$-stage thrust/weigth ratio, $(F / W)_{j}$, is obtained from

$$
F_{j}=(F / W)_{j} m_{T, j} g_{0}
$$

The total mass flow rate of propellants, $\dot{m}_{p r o p, j}$, is related to the thrust and to the specific impulse by 


$$
\dot{m}_{p r o p, j}=F_{j} /\left(I s p_{j} g_{0}\right)
$$

The fuel mass flow rate, $\dot{m}_{f u e l, j}$, limits the thrust levels, due to the relatively low regression rates of hybrid fuels. It is related to the total mass consumption rate of propellants and to the $O F_{j}$ (oxidizer/fuel) mass ratio, by the relation:

$$
\dot{m}_{f, j}=\dot{m}_{p r o p, j} /\left(1+O F_{j}\right)
$$

The oxidizer mass flow rate, $\dot{m}_{o, j}$, is calculated by

$$
\dot{m}_{o, j}=\dot{m}_{p r o p, j} O F_{j} /\left(1+O F_{j}\right)=\dot{m}_{p r o p, j}-\dot{m}_{f, j}
$$

The burning time, $t_{b, j}$, is obtained from

$$
t_{b, j}=m_{p r o p, j} / \dot{m}_{p r o p, j}
$$

The fuel and oxidizer volumes, $V_{f, j}$ and $V_{o, j}$, are calculated from their masses, i.e.,

$$
\begin{gathered}
V_{o, j}=m_{o, j} / \rho_{o, j}, \text { with } m_{o, j}=m_{p r o p, j} O F_{j} /\left(1+O F_{j}\right) \\
V_{f, j}=m_{f, j} / \rho_{f, j}, \text { with } m_{f, j}=m_{p r o p, j} /\left(1+O F_{j}\right)
\end{gathered}
$$

where $\rho_{f, j}$ is the fuel density and $\rho_{o, j}$ is the hydrogen peroxide density, which varies with temperature, pressure and peroxide concentration. In the next sections the subscript $j$ will be disregarded.

\section{A. Fuel chamber and nozzle}

The chamber mass depends on the paraffin grain geometry. The initial port diameter of the fuel grain, $D_{\text {int, }}(0)$, is calculated by

$$
D_{i n t, g}(0)=\left(4 \dot{m}_{o} / \pi G_{o}(0)\right)^{1 / 2}
$$

where $G_{o}(0)$ is the initial mass flow rate of oxidant per unit area in the fuel chamber, assumed as $250 \mathrm{~kg} / \mathrm{m}^{2} / \mathrm{s}$ for peroxide fed by a vortical injector.

The regression rate of a hybrid fuel is adjusted experimentally by

$$
\dot{r}(t)=a G_{o}^{n}(t)(m m / s)
$$

where $t$ is time and $a$ and $n$ are experimental constants. The regression rate, in general, varies with time, since the fuel port increases during burning. Consequently, for a constant oxidizer mass flow rate, the oxidizer flow rate per unit area, $G_{o}$, decreases with time. Assuming a single circular port, integrating Eq. (13) from $t=0$ to $t=t_{b}$, yields the fuel grain external diameter, $D_{\text {ext } g \text { : }}$

$$
D_{\text {ext }, g}=\left[(a / 1000)(4 n+2)\left(4 \dot{m}_{o} / \pi\right)^{n} t_{b}+D_{i n t, g}^{2 n+1}(0)\right]^{1 /(2 n+1)}
$$

and the grain length, $L_{g}$, is given by

$$
L_{g}=4 V_{f} /\left[\pi\left(D_{e x t, g}^{2}-D_{i n t, g}^{2}(0)\right)\right]
$$


The fuel chamber internal diameter is $D_{i n t, c}=D_{\text {ext,g }}+2 t_{\text {ins }}$, where $t_{\text {ins }}=0.003 \mathrm{~m}$ is assumed as the insulation thickness. The fuel chamber external diameter is $D_{e x t, c}=D_{i n t, c}+2 t_{w, c}$, where $t_{w, c}$ is the chamber wall thickness, given by $t_{w, c}=\left(1+f_{s}\right) P_{c} D_{i n t c} / \sigma_{c}$ where $\sigma_{c}$ is the yielding tensile of the tank material and $f_{s}$ is a safety factor for the chamber wall stress, assumed as $100 \%$.

The fuel chamber comprises the catalytic bed, injection plate, fuel grain section, pre-combustion section, postcombustion section and nozzle convergent. The catalytic bed decomposes the hydrogen peroxide at high temperatures, to ignite and burn the fuel grain. The pre-combustion, post-combustion and catalytic bed (including injection plate) lengths are assumed as $L_{\text {pre }}=0.5 D_{\text {int }, c}, L_{p o s}=0.7 D_{\text {int,c }}$ and $L_{c a t}=0.5 D_{\text {int }, c}$, respectively. The length of the nozzle convergent section is $L_{\text {con }}=0.5\left(D_{\text {int }, c}-D_{t}\right) / \tan \theta_{\text {con }}$ where $\theta_{c o n}=45^{\circ}$ is the convergence semi-angle.

Thus, the fuel chamber length of a stage is

$$
L_{c}=L_{g}+L_{p r e}+L_{p o s}+L_{c a t}+L_{c o n}
$$

and its mass is, approximately,

$$
m_{c} \cong 0.25\left(1+f_{b}\right) \pi \rho_{c}\left[L_{c}\left(D_{e x t, c}^{2}-D_{i n t, c}^{2}\right)+t_{w, c}\left(D_{i n t, c}^{2}-D_{t}^{2}\right) / \tan \theta_{c o n}\right]
$$

where $\rho_{c}$ is the fuel chamber wall density and $f_{b} \approx 0.2$ is a mass fraction corresponding to the catalytic bed.

The throat area is calculated from $A_{t}=F /\left(C_{F} P_{c}\right)$, where $C_{F}$ is the thrust coefficient, obtained from NASA CEA 2004 code, for a given nozzle expansion rate, $\varepsilon$, and chamber pressure, $P_{c}$. Therefore, the nozzle exit area is $A_{e}=\varepsilon A_{t}$ and the throat diameter is $D_{t}=\left(4 A_{t} / \pi\right)^{1 / 2}$.

Considering a conical nozzle, the nozzle divergent length and mass are approximated, respectively, by

$$
\begin{aligned}
& L_{d i v}=0.5\left(D_{e}-D_{t}\right) / \operatorname{tg} \theta_{D} \\
& m_{d i v}=0.5 \rho_{n o z} t_{w, d i v} \pi\left(D_{e}+D_{t}\right)\left(\left(D_{e}-D_{t}\right)^{2} / 4+L_{d i v}^{2}\right)^{1 / 2}
\end{aligned}
$$

where $\theta_{D}$ is the divergence semi-angle, $D_{e}$ is the nozzle exit diameter and $t_{w, d i v}=0.5 t_{w, c}$ is the average nozzle wall thickness.

\section{B. Oxidizer tank}

Spherical oxidizer tanks are used in the second and third stages, with internal diameter, $D_{\text {int, tko }}$, given by

$$
D_{\text {int, tho }}=\left(6\left(V_{o}+V_{u}\right) / \pi\right)^{1 / 3}
$$

where $V_{u} \approx 0.05 V_{o}$ is the initial ullage of the oxidizer tank.

The oxidizer pressure in the tank is $P_{o}=P_{c}+\Delta P_{o}$, where $P_{c}$ is the combustion pressure and $\Delta P_{o} \approx 0.2 P_{c} \mathrm{MPa}$ is the total pressure loss in lines, injection and valves. The wall thickness and the mass of the spherical oxidizer tank are, respectively,

$$
\begin{aligned}
& t_{w, t k o}=0.25\left(1+f_{s}\right) P_{o} D_{i n t, t o o} / \sigma_{t k o} \\
& m_{t k o}=\left(1+f_{t k}\right) \rho_{t k o}(\pi / 6)\left(D_{e x t, k o o}^{3}-D_{i n t, k o}^{3}\right)
\end{aligned}
$$


where $\sigma_{t k, o}$ is the yielding tensile of the tank material, $f_{t k} \approx 0.2$ is the tank mass fraction used for welding and support, and $D_{\text {ext,tko }}=D_{\text {int tho }}+2 t_{w, t k o}$ is the external diameter of the oxidizer tank.

A cylindrical tank with two hemispherical domes is used in the first stage. The total length, $L_{t k o}$, wall thickness, $t_{w, t k o}$, and mass, $m_{t k o}$, of the cylindrical tank are, respectively,

$$
\begin{aligned}
& L_{t k o}=D_{e x t, k o o}+L_{c, k t o} \\
& t_{w, t k o}=0.5\left(1+f_{s}\right) P_{o} D_{i n t, k o o} / \sigma_{t k o} \\
& m_{t k o}=\left(1+f_{t k}\right) \rho_{t k o}(\pi / 6)\left[\left(D_{e x t, t k o}^{3}-D_{i n t, k o}^{3}\right)+1.5\left(D_{e x t, t k o}^{2}-D_{i n t, k o}^{2}\right) L_{c, t k o}\right]
\end{aligned}
$$

where $L_{c, t k o}=4\left(V_{o}+V_{u}-(\pi / 6) D_{i n, t k o}^{3}\right) /\left(\pi D_{i n, t k o}^{2}\right)$ is the length of the cylindrical section.

\section{Pressurizing system}

The oxidizer is pressurized by a gas generator using $\mathrm{H}_{2} \mathrm{O}_{2}$ at $70 \%$ in mass decomposed at a catalytic bed. The pressurant mass is

$$
m_{\text {pres }}=\left(1+f_{\text {pres }}\right) P_{\text {pres }}\left(V_{u}+V_{o}\right) /\left(R_{\text {pres }} T\right)
$$

where $f_{\text {pres }} \approx 0.05$ is the pressurant fraction for filling the feeding lines and $R_{\text {pres }}$ is the gas constant of the decomposed pressurant. The liquid pressurant $\left(70 \% \mathrm{H}_{2} \mathrm{O}_{2}\right)$ is assumed at constant pressure $P_{\text {pres }}=1.2 P_{\text {oxid }}$, with density $\rho_{\text {pres }}$ and volume $V_{\text {pres }}=m_{\text {pres }} / \rho_{\text {pres. }}$. The internal diameter and the mass of the spherical pressurant tank are, respectively,

$$
\begin{aligned}
& D_{\text {int,lppes }}=\left(6 V_{\text {pres }} / \pi\right)^{1 / 3} \\
& m_{\text {thpres }}=\rho_{\text {thpres }}\left(1+f_{t k}\right)(\pi / 6)\left(D_{\text {ext, }, \text { ppres }}^{3}-D_{\text {int, thpres }}^{3}\right)
\end{aligned}
$$

A small helium tank with a blowdown ratio $r_{p}=P_{H e, i} / P_{H e, f}=5$ is used to pressurize the liquid $70 \% \mathrm{H}_{2} \mathrm{O}_{2}$. The final pressure at the helium tank is assumed $P_{H e, f}=1.2 P_{\text {pres }}$ and the initial helium volume, assuming an isothermal expansion process, is $V_{H e, i}=V_{\text {pres }} /\left(r_{p}-1\right)$, which is equal to the helium tank volume, $V_{t k H e}$. Then, the mass of helium is

$$
m_{H e}=1.2 r_{p} P_{\text {pres }} V_{\text {thHe }} /\left(R_{H e} T\right)
$$

and the mass of a spherical helium tank is

$$
m_{t k H e}=\rho_{t k H e}\left(1+f_{t k}\right)(\pi / 6)\left(D_{\text {ext, kHHe }}^{3}-D_{i n, t k H e}^{3}\right)
$$

where $D_{\text {ext, }, k H e}=D_{\text {int,kHe }}+2 t_{w, t k H e}$ is the external diameter and $\rho_{t k H e}$ is the material density of the helium tank.

\section{Stage case}

The total stage case length is, approximately,

$$
L_{\text {case }} \cong 1.1\left(L_{c}+L_{t k o}+D_{\text {ext }, \text { thHe }}+D_{\text {ext, thpres }}+L_{d i v}\right)
$$

which includes a $10 \%$ increase corresponding to spacing for control system, telemetry, valves, feeding lines, stage coupling and other devices. 
In the third stage it is included a fairing, assumed as cylinder with $0.8 \mathrm{~m}$ height and $0.6 \mathrm{~m}$ diameter. The internal diameter of the stage case, $D_{\text {int,case }}$, is assumed equal to the external diameter of the oxidizer tank plus $0.04 \mathrm{~m}$ for tank support rings. The external diameter of the stage case, $D_{\text {ext,case }}$, depends on material compression strength and on the applied compression force due to the rocket acceleration:

$$
D_{\text {ext, case }} \cong\left[D_{\text {int,case }}^{2}+4 m_{T} g_{0}(1+F / W) / \pi \sigma_{c}\right]^{1 / 2}
$$

where $D_{\text {int,case }}$ is the case internal diameter and $\sigma_{c}$ is the compression strength of the case material. The compression strength of the case was assumed to be equal to its yielding strength. Nevertheless, a minimum thickness of $2 \mathrm{~mm}$ was considered for all stages, for manufacturing purposes. The stage case mass is calculated by

$$
m_{\text {case }}=\rho_{\text {case }} L_{\text {case }}(\pi / 4)\left(D_{\text {ext,case }}^{2}-D_{\text {int,case }}^{2}\right)
$$

Therefore, the total inert mass of a stage is, approximately,

$$
m_{\text {inert }} \cong 1.1\left(m_{c h}+m_{t k o}+m_{H e}+m_{\text {pres }}+m_{\text {thpres }}+m_{\text {thHe }}+m_{\text {div }}+m_{\text {case }}\right)
$$

which also includes a $10 \%$ increase corresponding to the masses of the control system, telemetry, valves, feeding lines, stage coupling and other devices. Figure 1 shows a scheme of a typical hybrid rocket configuration.

Table 3 shows the initial conditions and Table 4 shows the mechanical properties of materials used for the mass distribution analysis. Titanium was used in all tanks, stainless steel was used in fuel chambers and nozzles, and carbon fiber was used in cases and fairing. Ground and air-launched rockets with three stages were compared in order to place a $20 \mathrm{~kg}$ payload into a low Earth circular orbit at $300 \mathrm{~km}$ height.

The propellants chosen were $98 \% \mathrm{H}_{2} \mathrm{O}_{2}$ and $\mathrm{C}_{20} \mathrm{H}_{42}$ paraffin mixed with $10 \%$ aluminum in mass. Aluminum mixture increases the specific impulse and displaces the optimum $O F$ ratio to lower values. Ref. (4) gives $a=0.0344$ $(\mathrm{mm} / \mathrm{s})\left(\mathrm{m}^{2} \mathrm{~s} / \mathrm{kg}\right)^{n}$ and $n=0.9593$ (non-dimensional) for paraffin burning with $84 \%$ hydrogen peroxide. The regression rate was multiplied by factor $0.98 / 0.84$ due to the richer peroxide solution used.

Assuming $P_{c}=2.5 \mathrm{MPa}, O F=6.5, F / W=2.5, C_{F}$ efficiencies of $93 \%$ and initial $f_{\text {inert }}=0.2$ in all stages, the masses and sizes of the main components and stages were calculated. A new inert fraction was calculated for each stage and compared to the previous one. If the difference was less than $0.01 \%$ the calculation was stopped, if not a new iteration was made. In general, 6 iterations were enough for convergence. Table 5 shows the final mass distributions and additional data of air and ground launched hybrid rockets to perform the assigned mission, using three stages.

Figures 2 and 3 compare the effects of $O F$ mass ratio on stage mass and on inert fraction, respectively, for ground and air launched rockets. Figures 4 and 5 show the effects of the $F / W$ ratio and chamber pressure, respectively, on mass and inert fraction of air launched rockets. Figures 6 and 7 show the effects of the $F / W$ ratio and chamber pressure, respectively, on length and diameter of air launched rockets.

It can be seen in Table 5 that the masses and sizes of air-launched rockets are significantly smaller, about $60 \%$ of the masses and $82 \%$ of the sizes of ground launched rockets. The payload fraction and total lengths of ground and air launched rockets are about $0.26 \%$ and $18 \mathrm{~m}$, and $0.43 \%$ and $14.7 \mathrm{~m}$, respectively. Figures 3 and 4 depict that the minimum total mass is found with $O F=6.5$, corresponding to the maximum Isp, whereas the inert fractions are lower with $O F=7$. Inert fractions for first stages are below $20 \%$ whereas third stages present inert fractions above $25 \%$. The large inert fractions and low payload ratios obtained using the preliminary mass distribution model can be explained by the conservative parameters adopted. Lower $F / W$ ratios and lower chamber pressures yield smaller sizes and masses for all stages. First stage tanks could have larger diameters in order to reduce the total lengths. Using more advanced materials would also allow to obtain lower masses and sizes.

It is seen that the inert fraction is strongly affected by the oxidant pressures, especially in the first stages, whereas variations on $F / W$ and $O F$ in the ranges considered do not show significant effects on inert fractions and sizes, for all stages. 
Table 3. Initial conditions for 3-stage hybrid rockets.

\begin{tabular}{|c|c|c|c|c|c|c|}
\hline & \multicolumn{3}{|c|}{ Ground launched } & \multicolumn{3}{c|}{ Air launched } \\
\hline$\Delta V_{\text {total }}(\mathrm{m} / \mathrm{s})$ & \multicolumn{3}{|c|}{9300} & \multicolumn{3}{c|}{8700} \\
\hline Stage & $1 \mathrm{st}$ & $2 \mathrm{nd}$ & $3 \mathrm{rd}$ & $1 \mathrm{st}$ & $2 \mathrm{nd}$ & $3 \mathrm{rd}$ \\
\hline$\Delta V(\mathrm{~m} / \mathrm{s})$ & 3100 & 3100 & 3100 & 2900 & 2900 & 2900 \\
\hline Expansion rate $(\varepsilon)$ & 10 & 40 & 60 & 10 & 40 & 60 \\
\hline$I s p_{\text {eff }}(\mathrm{s})$ & 257 & 290 & 297 & 257 & 290 & 297 \\
\hline
\end{tabular}

Table 4. Materials and mechanical properties.

\begin{tabular}{|c|c|c|c|c|}
\hline Material & $\begin{array}{c}E \\
(\mathrm{GPa})\end{array}$ & $\begin{array}{c}\sigma \\
(\mathrm{MPa})\end{array}$ & $\begin{array}{c}\text { Density } \\
\left(\mathrm{kg} / \mathrm{m}^{3}\right)\end{array}$ & Item \\
\hline Carbon fiber & 228 & 3800 & 1810 & Case \\
\hline 4130 steel & 200 & 635 & 7830 & Fuel chamber/nozzle \\
\hline Titanium & 115 & 790 & 4460 & Tanks \\
\hline
\end{tabular}

$E=$ bulk modulus; $\sigma=$ tensile yield strentgh.
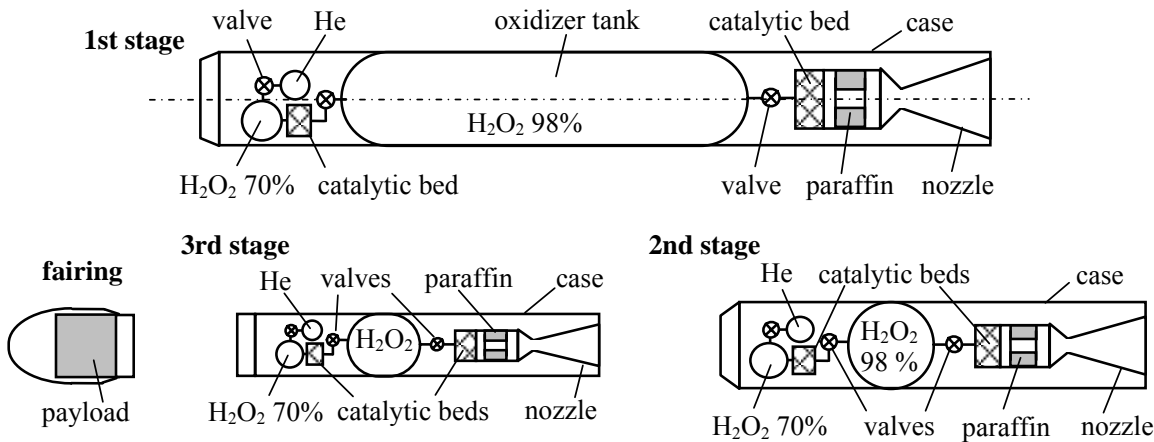

Figure 1. Three stage hybrid rocket configuration scheme.

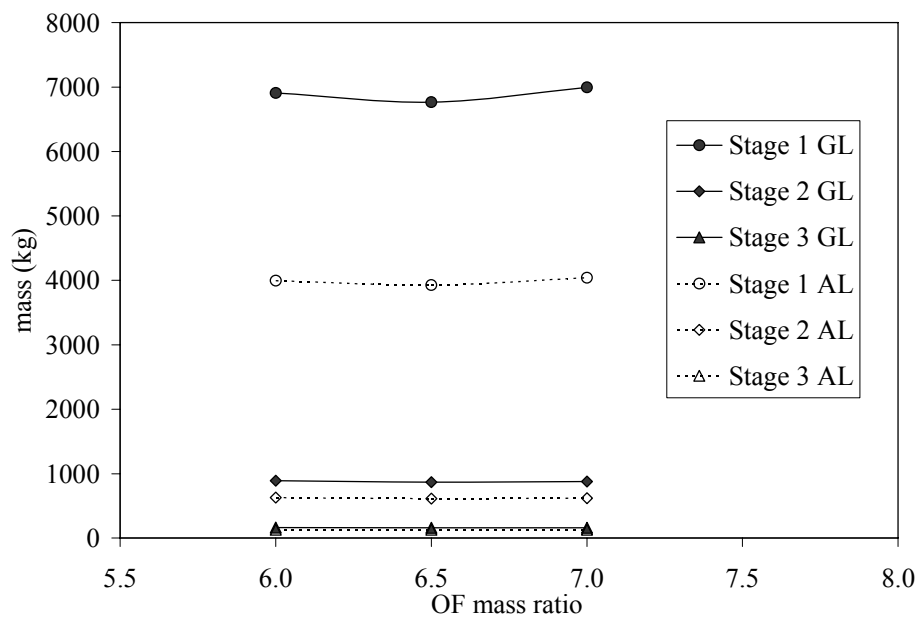

Figure 2. Effects of $O F$ mass ratio on stage mass of ground launched (GL) and air launched (AL) hybrid rocket stages, with $P_{c}=2.5 \mathrm{MPa}$ and $F / W=2.5$. 


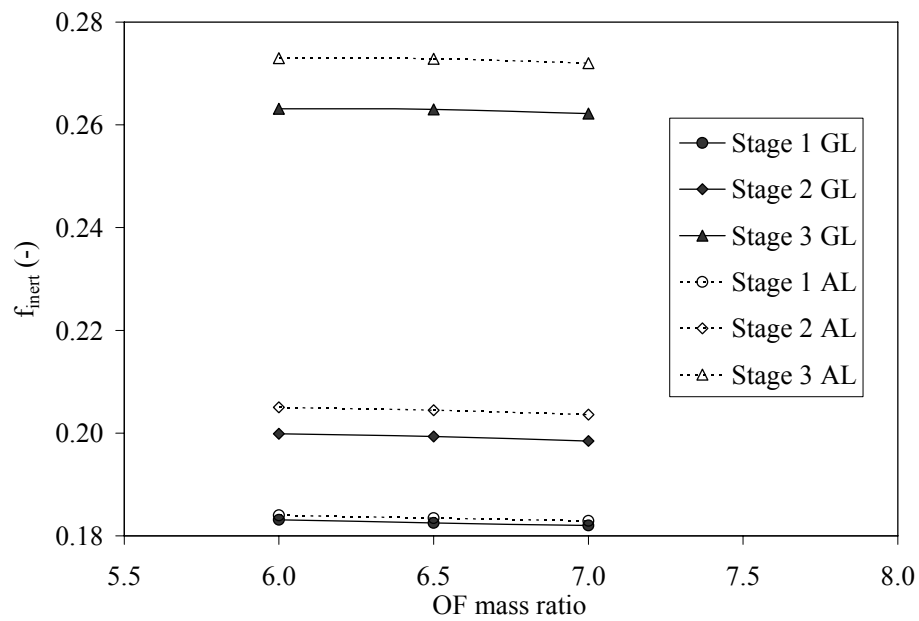

Figure 3. Effects of $O F$ mass ratio on inert fraction of ground launched (GL) and air launched (AL) hybrid rocket stages, with $P_{c}=2.5 \mathrm{MPa}$ and $F / W=2.5$.

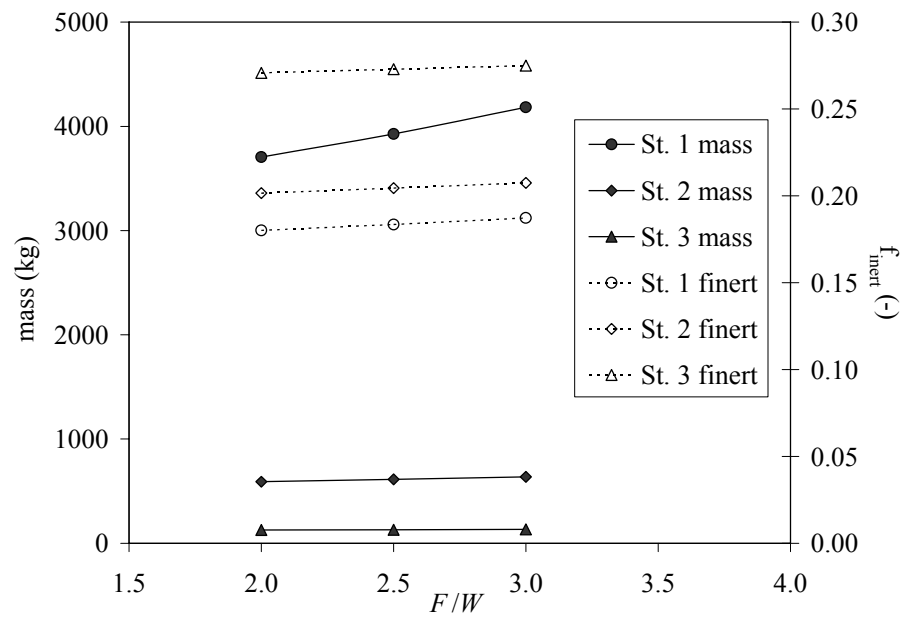

Figure 4. Effects of $F / W$ ratio on stage mass and inert fraction of air launched hybrid rockets, with $\boldsymbol{P}_{c}=2.5$ MPa and $O F=6.5$.

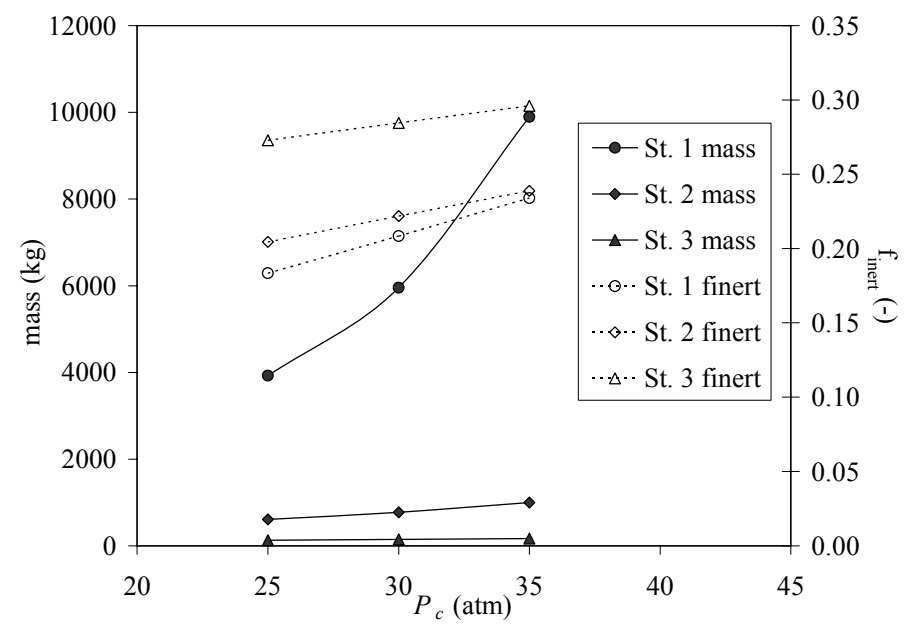

Figure 5. Effects of chamber pressure on stage mass and inert fraction of air launched hybrid rockets, with $O F=6.5$ and $F / W=2.5$. 


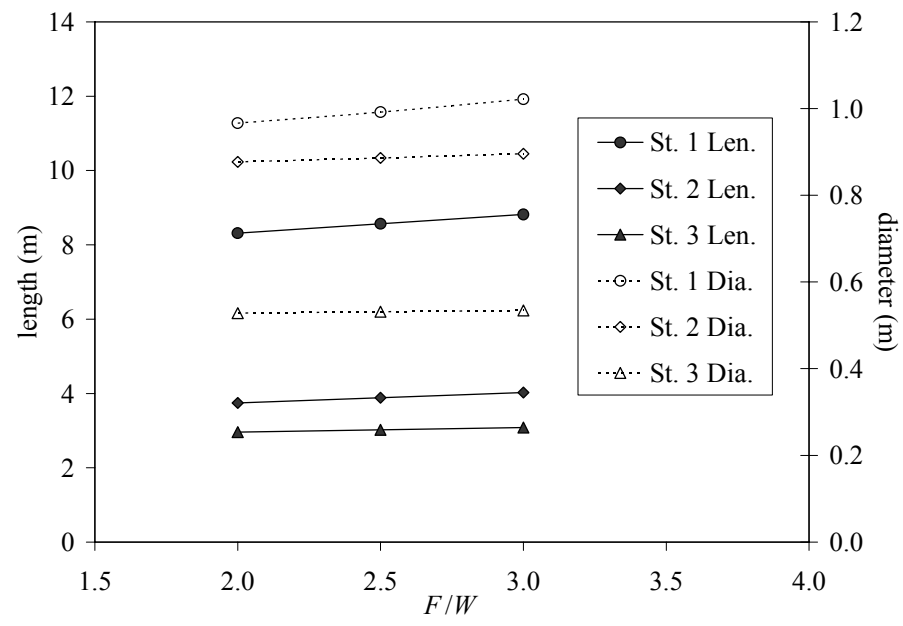

Figure 6. Effects of $F / W$ ratio on stage length and diameter of air launched hybrid rockets, with $P_{c}=2.5 \mathrm{MPa}$ and $O F=6.5$.

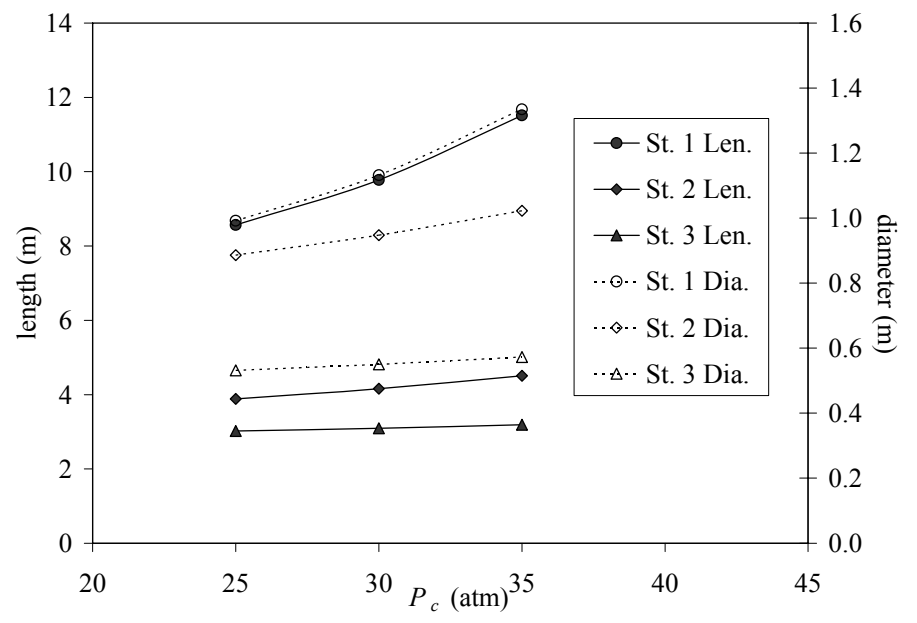

Figure 7. Effects of chamber pressure on stage length and diameter of air launched hybrid rockets, with $O F=$ 6.5 and $F / W=2.5$.

\section{Conclusions}

A preliminary analysis of the mass distribution and sizing of hybrid propulsion systems was described. Paraffin with $10 \%$ aluminum and $98 \%$ hydrogen peroxide were used as propellants. Three stage air launched hybrid rockets and ground launched hybrid rockets were compared for placing a $20 \mathrm{~kg}$ nanosat into a low Earth circular equatorial orbit at $300 \mathrm{~km}$. An iterative process was used to obtain the mass distributions and the performance characteristics of hybrid rockets. The results have indicated that the total initial mass is about $7800 \mathrm{~kg}$ for a ground launched hybrid rocket and $4700 \mathrm{~kg}$ for an air launched hybrid rocket. Such a low mass in the case of air launched rockets would permit the use of relatively light airplanes, with great flexibility on launching schedule and launching sites on the equator line. The results obtained can be used as input for more detailed performance analysis, considering small components, more efficient materials, less conservative parameters, and variations on specific impulse, ambient pressure and drag coefficient along specific trajectories. 


\section{References}

${ }^{1}$ Karabeyoglu, A., Zilliac, G., Castellucci, P, Urbanczyk, P., Stevens, J., Inalhan, G., Cantwell, B, J., 2003, “Development of High-Burning-Rate Hybrid-Rocket-Fuel Flight Demonstrators, 39th AIAA/ASME/SAE/ASEE Joint Propulsion Conference, Huntsville, AL, USA.

${ }^{2}$ Karabeyoglu, A., Zilliac, G., Cantwell, B.J., Dezilwa, S., Castellucci, P., 2003, "Scale-up Tests of High Regression Rate Liquefying Hybrid Rocket Fuels", American Institute of Aeronautics and Astronautics, Aerospace Sciences Meeting and Exhibit, Nevada, USA.

${ }^{3}$ Karabeyoglu, A., Zilliac, G., Cantwell, B. J., Dezilwa, S., Castellucci, P., 2004, "Scale-up Tests of High Regression Rate Paraffin-Based Hybrid Rocket Fuels", Journal of Propulsion and Power, v.20, n.6, p. 1037-1045.

${ }^{4}$ Brown, T. R., Lydon, M. C., 2005, "Testing of Paraffin-Based Hybrid Rocket Fuel Using Hydrogen Peroxide Oxidizer", AIAA Region 5 Student Conference, Wichita, USA.

${ }^{5}$ Santos, L. M. C., Almeida, L. A. R, Veras, C. A. G., 2005, "Design and Flight Test of a Paraffin Based Hybrid Rocket", Proceedings of the 18th International Congress of Mechanical Engineering, CD-ROM, ABCM, Rio de Janeiro, Brasil.

${ }^{6}$ Mccormick, A., Hultgren, E., Lichtman, M., Smith, J., Sneed, R., Azimi, S., 2005, "Design, Optimization, and Launch of a 3" Diameter N2O/Aluminized Rocket", AIAA/ASME/SAE/ASEE Joint Propulsion Conference and Exhibit, 41, Tucson, Arizona.

${ }^{7}$ Gouvêa, L. H., 2007, "Performance analysis of a hybrid thruster using paraffin and hydrogen peroxide as propellants", Master Dissertation, INPE, São José dos Campos, SP, Brazil.

${ }^{8}$ Davis Jr, N. S., Keefe, J. H., 1956, "Concentrated Hydrogen Peroxide as a Propellant”, Industrial and Engineering Chemistry, v.48, n.4, pp. 745-748.

${ }^{9}$ Wernimont, E., Ventura, M., Garboden, G., Mullens, P., 1999, Past and Present Uses Of Rocket Grade Hydrogen Peroxide, International Hydrogen Peroxide Propulsion Conference, West Lafayette, USA.

${ }^{10}$ Heister, S. D., Wernimont, E. J.,Rusek, J. J., 1998, “High Test Peroxide Hybrid Rocket Research", Hydrogen Peroxide Propulsion Workshop, Surrey, England.

${ }^{11}$ Wiliams, G., Macklin, F., Sarigul-Klijn, M., Sarigul-Klijn, N., Benson, J., 2004, “Almost There: Responsive Space”, Paper Number RS2-2004-A024, Responsive Space Conference, Los Angeles, CA, USA.

${ }^{12}$ Ventura, M. C., Wernimont, E., Heister, S., Yuan, S., "Rocket Grade Hydrogen Peroxide (RGHP) for use in Propulsion and Power Devices - Historical Discussion of Hazards", Paper AIAA 2007-5468, 43rd AIAA/ASME/ SAE/ASEE Joint Propulsion Conference \& Exhibit, Cincinnati, OH, 8 - 11 July 2007.

${ }^{13}$ Humble, R. W., Altman, D., 1995, “Space Propulsion Analysis and Design”, Ed. M. A. Hollander, pp. 365-370.

${ }^{14}$ CEA - Chemical Equilibrium with Applications, 2004, Glenn Research Center, NASA, Cleveland, OH, USA, http://www.grc.nasa.gov/WWW/CEAWeb/ceaHome.htm, access in October 2007.

\section{Acknowledgments}

The authors acknowledge the financial support of FAPESP in Brazil (São Paulo State Foundation for Research Support). 